\title{
The Effects Of Calorie Count Display On Consumer Eating Behavior: Would It Solve The Obesity Problem? An Empirical Perspective
}

\author{
Elias G. Rizkallah, Ph.D., La Sierra University, USA
}

Kimberly Feiler, MSHS., La Sierra University, USA

\begin{abstract}
Obesity in the United States and around the world is getting to be of epidemic proportions, with major economic, social, and psychological impacts on society. Its impact is evident in cost of health care, opportunity cost of lower productivity, emotional and physical suffering, and shorter life expectancy. Although obesity is the result of individual behavior, efforts to reduce it are initiated by many concerned parties. The question is, how effective are these efforts? The researchers are interested in knowing individuals' attitudes about these efforts, specifically, the latest regulation of displaying calorie counts on menus of restaurants and its effects on their behaviors. The survey also covered consumers' opinions regarding obesity, its causes, and what can be done about it. Specifically, the purpose of this study is to determine the effects of calorie count display on consumers' eating habits, consumers' attitude towards obesity as a societal concern, and their views about who is to blame and who should do something about the obesity problem. The study surveyed 226 consumers in the Southern California area. Results are analyzed, discussed, and used as basis for making recommendations to all parties concerned (i.e., individuals and families, government agencies, healthcare organizations, and food companies and restaurants) regarding their role to reduce obesity and its adverse economic, social, and psychological impact on society.
\end{abstract}

Keywords: Calorie Count on Menus; Food Industry Regulation; Consumer Eating Habits; Obesity; Social Marketing

\section{INTRODUCTION}

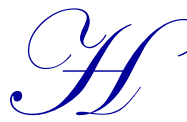

ow interesting?! What was historically considered a sign of prosperity and good times today is a sign of misery and depression. The world is faced with a serious epidemic that has taken hold of many societies, including the United States (US) - obesity. Obesity rates worldwide have escalated to epidemic proportions (World Health Organization [WHO], 2007). In the US alone, more than 72 million people are obese (Centers for Disease Control and Prevention [CDC], 2011). It is estimated that more than 35\% of American adults over 20 years of age are obese (CDC, 2012). This has profound medical and economic consequences. Obesity-related medical costs were just under $\$ 150$ billion in 2008, with obese people spending on average over $\$ 1,400$ more than their normal-weight counterparts (CDC, 2011; Finkelstein, Trogdon, Cohen, \& Dietz, 2009). In California, obesity-related medical costs have risen to more than $\$ 15$ billion; and it has been suggested that medical costs could be reduced by up to $11 \%$ if obesity could be removed from the picture (Rettner, 2011). About $85 \%$ of diseases, such as (a) cardiovascular disease, (b) cancer, (c) diabetes, (d) osteoporosis, (e) obesity, (f) anxiety and (g) depression, are preventable through a healthy diet and exercise (Biddle, Gorely, \& Marshall, 2009; "Sitting Can Shorten," 2010). 
Given the serious implications of consumers' expanding waistlines, it is critical to gain an understanding of factors fostering caloric over-consumption, such as, quantity and quality of food consumed, irregular eating habits, food additives, psychological depression, etc., and what can be done about it. For example, in an attempt to help, Kraft introduced small package sizes of low calorie snack products in 2004. Since then, other companies have joined in, and within three years, annual sales of these small packages surpassed \$200 million (Meitus \& Dedrick, 2006). The overwhelming success of these small package options is likely due to the perception that they allow consumers to indulge in foods they love while feeling virtuous for eating only small amounts. Indeed, recent research found that consumers intuitively believe that small packages can limit caloric intake (Coelho do Vale, Pieters, \& Zeelenberg, 2008; Scott et al., 2008). However, Argo and White (2012) found this has a moderate effect on appearance and self-esteem - that is, the self-worth a person derives from his or her body image and weight.

As obesity continues to be cited as a national epidemic, the Food and Drug Administration (FDA) has come forward with guidelines directed at informing customers in restaurants of what they are going to eat prior to purchasing. According to new guidelines, a business with 20 or more locations is required to post calorie counts in the same size type as the food item or its price. Vending machines are also to transparently display the calorie counts on food items so consumers are able to review it before making a purchase. While these guidelines are geared towards lessening the obesity rate by informing customers of potentially unhealthy choices, the question is, are these guidelines and information, in fact, causing consumers to modify their behaviors, and making choices based on this information? If the answer is yes, the marketing concept argues that food industries should take action regarding the American health issues caused by the food they offer. If consumers transform the way they approach diet and health, this may transform traditional food manufacturers into healthy dietary centers via understanding what customers really want. This transformation will be useful in developing "good food" for a healthier societyphysically, psychologically, and financially — as well as assist companies in determining marketing strategies aimed at increasing sales levels by utilizing the customer decision process (e.g., changing menus, recipe alterations, portion sizes, etc.). Thus, a potential value of this research is to find out if consumers' behaviors were modified based on calorie display, and how individuals modified their behavior. If the changes in consumer behavior were large enough to change business practices, then to what degree should restaurants change their business practices in order to stay competitive, based on their understanding of consumer behavior.

The study sheds light on some realities of consumer behavior and market dynamics that may help all parties involved do the right thing - consumers change their eating habits, food industry change its practices, policy makers do their role effectively, and all other support systems (e.g., family, schools, media, health care providers, etc.) boast and celebrate such actions. The only limitation is that these parties simply may not be interested or willing to resolve the problem.

\section{LITERATURE REVIEW}

Previous research efforts have shown that posting calories on the menu influences customer buying and eating decisions (Benelam, 2009; MacQueen, 2010; Roberto et al, 2010; Skenazy, 2008; Zarick, 2011). The majority of fast food or chain restaurants have seen a documented impact from customers' response to calorie count on the menu (Zarick, 2011). Some of the current marketing strategies have been considered as a response to government regulation on labeling calorie count, such as introducing healthier menu options, new menu design, new food choices, and even new opportunities to the business in response to customers who pay attention to calorie counts. Up to $90 \%$ of customers stop and consider the food they are about to eat because of the calorie information posted, but not all will change their behavior (Zarick, 2011). Overall, by posting calorie information on menus, customers now have the option to make more-informed decisions about how many calories are in their meals.

In New York City, approximately one-sixth of the customers changed their mind to look for a lower calorie food on the menu when they paid attention to the calorie counts. Since then, the mean calories-per-purchase has declined significantly at fast food chain restaurants (Zarick, 2011). Research and surveys suggest that the calorie counts on the menu assist customers in choosing food, as well as style of restaurants. Customers also support that restaurants post fat and sodium content in restaurant foods (MacQueen, 2010; Zarick, 2011). Surprised by the amount of calories in certain food items versus their expectations, some customers look for alternative choices, even for an item that is 100 calories less than the original order they intended to purchase. In another study, it was found 
that some people have decided to keep their afternoon treat, and skimp on dinner, others have decided to eliminate some items and opt for healthier ones (Pulos \& Leng, 2010; Skenazy, 2008). In Spring 2009, Craig and Caraway (2011) found $15 \%$ of fast food customers surveyed said they used posted calorie information to make food buying decisions. These customers purchased 106 fewer calories than those who did not see or use the calorie information, and customers at three major fast food chains significantly reduced the calorie content of food items purchased. However, there was no significant change in calories purchased over all food chains (Craig \& Caraway, 2011).

Bollinger, Leslie, and Sorensen (2011) studied mandatory calorie postings and showed that it caused average calories per transaction to fall by $6 \%$ at Starbucks. Average beverage calories per transaction did not substantially change, but average food calories per transaction fell by $14 \%$. Three quarters of the reduction in calories per transaction was due to consumers buying fewer items, and one quarter was due to consumers substituting towards lower calorie items (Bollinger, Phillip, \& Sorensen, 2011).

In other studies, when menus posted no calories, consumers ended up ordering and eating the most number of calories during a meal, as well as eating the most number of calories in a post-meal snack. When menus posted calories, but did not provide a number for recommended daily caloric intake for an average adult, consumers ordered and ate less than diners whose menus did not include calorie counts; these groups also ate about the same amount of calories in a post-meal snack. When menus posted calories and recommended daily caloric intake for an average adult, consumers ordered and ate 14\% less calories during the meal and in a post-meal snack (Hellmich, 2009; Roberto et al, 2010).

Many restaurants have introduced changes as a response to customers' concern about health, even before the calorie display requirement. For example, Subway leverages healthy food options by offering a menu with a twist on traditional sub sandwiches without sacrificing flavor, which has resulted in positive response from customers. Their customers have positively responded to the addition of lower-calorie sandwiches, with a pattern shift of how customers order from the menu (Thorn, 2010).

Other chains have made changes as well: Quiznos launched their 500-calorie or less sandwiches, McDonalds and Carl's Jr. have added salads, and Burger King included apple fries as a healthy alternative to French fries on their menus (Miles, 2010). Restaurants, particularly the quick service restaurants, are aware of this lowcalorie trend and have responded to the market to accommodate it. Menu diversity can engage regular and new customer base; and restaurants need to adapt to trends to stay competitive in the market.

Regarding how the calorie information is displayed or delivered, it has been found that "clear, user-friendly information should be available at the point of sale and that consumers did not want to have to ask for this or to refer to a company's website" (Benelam, 2009, p. 289). In another study looking at children's fast food menu choices, it was found children could more easily identify "a heart symbol on the menus" (symbolizing a "healthy menu option") than they could understand nutrition information (including calorie and fat content) in traditional format (Stutts, Zank, Smith, \& Williams, 2011, p. 61). Viewing the heart symbol lowered customers' calorie and fat intake, whereas viewing nutritional information elicited no change.

Summing up, it is evident that the addition of calorie counts to menus causes behavioral modifications in consumers - several studies demonstrated that anywhere from $6 \%$ to $15 \%$ of consumers changed what they would purchase based on the existence of calorie counts. Though this is not a large change, it is a step in the right direction toward helping reduce obesity and obesity related health issues. Although the food industry has responded to the regulation, it is our belief that they can do more and be more creative to genuinely help solve the obesity problem.

This brief literature review is limited in its focus on the impact of calorie display and restaurants' strategies on consumer behavior; but let us not forget the impact of other parties, such as health care organizations, the packaged food industry, and social systems, to help reinforce the change as proposed in our theoretical frameworkthat integrative and coordinated efforts may help reduce obesity and its problems. 


\section{THEORETICAL FRAMEWORK}

Although obesity is a societal problem, it is attributed to the individual, and is due to either a health problem (not addressed in this study) or due to individual eating habits and preferences. Since the study is focused on the latter, and how the consumer is influenced by displaying the calorie counts on menus, the theoretical framework is based on the following argument: to reduce obesity, consumer eating habits need to change and a change in behavior requires an intention change and attitude change. Based on Fishbein's model of attitude formation and the theories that followed (e.g., the theory of reasoned action, the theory of trying) highlighted the many factors that may interfere between intention and behavior, in particular the issue of social pressure - the power of other people to influence behavior (Fishbein, 1983; Holbrook \& Havlena, 1988; Shimp \& Kavas, 1984). If all parties involved assist/influence/educate the individual to change (a) attitude, (b) behavioral intentions, and eventually (c) behavior (eating habits and food choices), obesity will be reduced.

\begin{tabular}{|c|c|c|}
\hline Government agencies & Attitude Change $\longrightarrow$ Intention Change & Consumer \\
\hline Health care organizations & assisted oy mintegrative $\alpha$ coorumated enorts. & Dentavior \\
\hline Packaged food companies & $\begin{array}{ll}\text { - } & \text { Lessen food additives } \\
\text { - } & \text { Reduce calorie content }\end{array}$ & \\
\hline Restaurants & - Motivate physical activity & D- \\
\hline Social support systems & - Regulate with reason & $\begin{array}{l}\text { Keduce } \\
\text { Obesity }\end{array}$ \\
\hline
\end{tabular}

In examining studies and efforts done by multiple parties to reduce obesity and its impact on society-more chaos than harmony, more individualistic than integrative efforts are manifested in handling this issue - are most likely due to differences in interest and lack of honesty. The food industry will claim that their cost will be higher due to short shelf life of food products if they don't use preservatives and other chemicals to maintain the integrity of the product over long periods of time. For restaurants, the more customers eat, the higher their ticket value will be, and the higher sales and profits will be - so why should restaurants care? Customers are the decision makersthey know the dangers of obesity, but they still love high calorie food. For the health care industry and pharmaceutical companies, obesity is the source of disease, and ironically leads to more business for them. Their claim is that, although they keep telling people of its danger, the people do not listen. For government agencies, they claim they are doing the maximum, but they have a dilemma of instituting more regulations (that may be considered interference with personal freedom), and implementing complicated roadblocks for businesses. For charitable organizations and social support systems, they claim they are doing their best in creating awareness, but that it boils down to individual consumptive decision. So, what should be done-give up? The answer is, "No!" Given that obesity is a global and national problem invading the fabric of our society, and that it touches all people in one way or another, something must be done. The theoretical model presented here calls for honest leadership, integrative efforts, and follow up. Since individual behavior is the focus, this study will shed light on what these parties might do to help change the individual's behavior, thus reducing obesity and its impact.

\section{METHODOLOGY}

The authors started the study with a focus group and extensive literature review as exploratory research that assisted in uncovering all issues involved in, influencing factors of, and motivations that play a role in consumers' decision making process, with particular regard to the purchase of food, and eating habits and preferences. The exploratory research helped in developing the survey questionnaire, which was used to collect the primary data. Data for this study was collected from 226 adults in the Southern California region, mainly the Inland Empire area. Respondents were randomly intercepted in fast food restaurants, sit-down (slow service) restaurants, and shopping malls/plazas. The locations were randomly selected of all locations characterized as places of attraction of a diverse population. To enhance randomness, the places were visited at different times of the weekdays and weekends. An incentive of $\$ 3.00$ cash was provided to each individual to complete the questionnaire. A total of 271 individuals 
were approached, some declined, and 226 completed the questionnaire to the extent that it is useful for the analysis. The researchers believe that the sample size and random process are acceptable for this limited study. The primary data collected via the questionnaire was analyzed, reported, and used as the basis for the final recommendations.

The survey utilized a self-administered questionnaire consisting of structured questions. The questionnaire first addressed some general questions about the respondents' eating habits, frequency of eating outside the home, restaurant choice and reasons, level of awareness of food calorie count, effects of calorie count on their behavior, who and how the parties concerned may help reduce obesity and its problems, etc. These questions were then followed by a set of attitudinal statements (using 5-point Likert Scale ranging from strongly agree to strongly disagree) pertaining to the issues in the study. Finally, the questionnaire ended with a few questions about the respondents' demographics. All questions and scales used were pre-tested, and the whole questionnaire was subjected to multiple pretests to ensure that it was error-free in form and content, and followed the scientific methods of questioning.

\section{RESULTS ANALYSIS}

Sample Demographics: The demographics of the surveyed respondents are as follows: $58.6 \%$ were females and $41.4 \%$ were males; $76.9 \%$ were born in the U.S., and $23.1 \%$ outside the US. Fifty two percent of respondents were married, $34.4 \%$ were single, and $12.9 \%$ were divorced, separated, or widowed. Forty six percent of respondents have children living with them at home. Sixteen percent of respondents live alone, $66 \%$ live in households consisting of 2-4 persons, and about 18\% live in households of more than 5 persons. Regarding educational levels of the respondents, $11.9 \%$ completed high school or lower, $33.8 \%$ completed some college or technical education, $26.2 \%$ completed college, and 28\% earned graduate degrees or higher. Age distribution is as follows: $20.4 \%$ were 18-25 years, $21.7 \%$ were $26-35$ years, $24 \%$ were $46-55$ years old, and 17.6 were 66 years and older. Respondents reported that they worked in 28 different positions across at least 10 different fields of work, and some of them (about 7.8\%) were retired. The dominating fields of work were education, medical, and government (about $45 \%$ of all respondents).

Majority of the respondents were Caucasian (41.8\%); Hispanic/Latino origins made up 24.5\%; African Americans, 15.5\%; and Asians/Pacific Islanders, Native Americans, and others, 18.2\%. Regarding the annual household income levels reported, $26.3 \%$ made $\$ 25,000$ or less, $23.9 \%$ made between $\$ 25,001$ and $\$ 50,000,25.4 \%$ made between $\$ 50,000$ and $\$ 100,000$, and $24.4 \%$ made over $\$ 100,000$.

Of the sample, at least $31.2 \%$ could be considered overweight/obese, with weight at $181 \mathrm{lbs}$. or more for either man or woman, with only $8.6 \%$ of the respondents reporting their height as 6 feet or taller.

Findings: In the study, it is important to note that all variables in the questionnaire were cross-tabulated with the demographic variables to check for any significant differences among the different demographic groups. Few of the differences were significant and were mentioned throughout the presentation of the findings below.

Behavior: Only $10 \%$ of the sample never dined in a fast food restaurant; $77.5 \%$ dined less than 5 times per week, and about $9.3 \%$ dined 6-10 times per week. As for sit-down restaurants, $88.4 \%$ of respondents dined less than 5 times per week, and 7.4\% reported never dining in a sit-down restaurant. When asked to rank the reasons for eating in a fast food restaurant, $68.1 \%$ ranked convenience as first, while cravings was ranked first by $20.8 \%$, and only 7.4\% ranked high calorie options as their first reason to eat in a fast food restaurant. In choosing a sit-down restaurant, respondents rank quality as first (45\%), taste as second (41\%), and customer service as third (21\%).

On how important each of the following factors - taste, price, calories, and portions was (on a scale from 1 "not important" to 7 "very important") when purchasing food, $90.3 \%$ reported taste (mean $=6.41$ ), 55.6\% reported price $($ mean $=5.55), 38.5 \%$ reported calories $($ mean $=4.71)$, and $36.9 \%$ reported portions $($ mean $=4.64)$ as important or very important. It is to be noted that quantity of food as a reason for choosing a restaurant differed significantly with education level $(\mathrm{p}=.001)$ and household income $(\mathrm{p}=.001)$. Results showed that higher education level and higher income were associated with lower importance given to food quantity. In addition, males were significantly more likely than females to place importance on large portion sizes $(\mathrm{p}=.001)$. 
The majority of respondents typically dined with $1-2$ persons $(47.3 \%)$ or 3-4 persons (31.9\%), and 9.3\% dined with groups of 5 persons or more; $11.5 \%$ dined alone. There was a significant relationship between number of persons living at home and the number with which respondents dined; they went hand in hand $(p=.000)$. Also, the younger the respondents (age 18-45 years), the higher the number of persons dined out with $(\mathrm{p}=.000)$ versus other age groups. Forty-six percent reported that the people they ate with influenced their decision, versus $54 \%$ reported that the people they ate with had no influence on their final food choice decision. Such information may help in utilizing friends and family influences in changing eating habits to reduce obesity.

Knowledge and health consciousness: On a scale from 1-10, 66.2\% reported 7-10 rating of being health conscious (mean $=6.88$ ), and $12 \%$ considered themselves not health conscious. Over $28 \%$ of respondents tried to watch what they eat. However, only $7.4 \%$ reported they would choose a healthy alternative all the time. When asked about the number of calories per day consumed on average, $63.3 \%$ said they did not know, versus $36.7 \%$ said "yes." Those who responded "yes" were asked to provide a number; responses ranged from 1000-4500 calories per day, and averaged 1935 calories per day. Such information may indicate that respondent knowledge has been ill-informed about how much they really consume. Eighty-eight percent of respondents knew about the regulation regarding displaying calorie information on menus. Twenty-eight percent reported they exercise on a regular basis. When asked how many days per week they exercised, $8.3 \%$ of respondents did not exercise at all, $20.6 \%$ exercised 1-2 days per week, 59.7\% exercised 3-5 days, and 11.4\% exercised 6-7 days of the week. It should be reminded that this was based on self-reporting. These inconsistencies in reporting somehow indicated that respondents reported their "wishful thinking;" however, there is room for stronger commitment to physical activities as a way to increase calorie output and reduce obesity.

Interest in calorie count display, usage frequency, and associated actions: Seventy-six percent of respondents cared to see the calorie counts displayed on the menu of a sit-down restaurant; $83.6 \%$ would like to see it on a fast food restaurant menu; $88.7 \%$ cared to see calorie counts displayed on packaged food. Almost the same percentages of respondents as reported above said they cared to see nutritional information on menus and on packaged food. Regarding the frequency of using nutritional information on the label when purchasing food, on a scale from 1 (not at all) to 7 (all the time), the mean of responses was 4.73 with $38.9 \%$ reporting "all the time" or "most of the time," $14.7 \%$ "not at all," and the remaining $46.4 \%$ reported "occasional use." When respondents were asked what they did if fast food restaurants informed them of nutritional facts on the menu, only $10.8 \%$ reported that they would ignore the information, $54.5 \%$ would believe them, $42.3 \%$ would purchase their food, and $66.8 \%$ would make a healthier choice. This is a sign that respondents did not mind the information, were willing to use it, and some would favor restaurants that provided such information. Sixteen percent of respondents favored restaurants that included calorie labeling for meals.

Almost 19\% of respondents were aware of calorie counts. Calorie counts were not a concern and did not mean anything to $23 \%$ of respondents. However, it was found that highly educated respondents reported strong disagreement with this statement than others with lower levels of education $(\mathrm{p}=.001)$. Only $12.2 \%$ took into account their calorie intake throughout the day, and $26 \%$ did not skip meals to reduce daily calorie intake. Twentythree percent read calorie counts on packaged foods.

Sixty-five percent of respondents reported they changed their decision based on calorie information on menus. Of those, $46.4 \%$ reported changes to their food choice, and $52.3 \%$ reported changes in both beverage and food choices. Over $24 \%$ drink water now that they see the beverage calorie counts on menus. Females tended to change their decisions more than males $(\mathrm{p}=.001)$, tended to order smaller portions than males $(\mathrm{p}=.001)$, and tended to order lower calorie options more often than males $(\mathrm{p}=.001)$. Regarding the magnitude of that change, $30.1 \%$ reported that they changed a little, $45.4 \%$ moderately, and $24.5 \%$ changed a lot based on the calorie display. As for how they changed, most common changes were (of a list of options and checking all that applied): ordered smaller portions $(65.2 \%)$, total change in food ordered $(62.2 \%)$, reduced course $(59.6 \%)$, and shared course $(57.4 \%)$. The first reason respondents chose lower calorie food was for healthier choices (32.6\%), followed by watching their weight (23.0\%), feeling better when eating healthy (17.8\%), and feeling better about oneself (10.0\%). A very small percentage mentioned the reason they chose lower calorie food was taste, trend, friends and family eating healthy, or that they were on a restricted diet. In regards to what food contents respondents were concerned about when ordering food, calories was the highest $(45.2 \%)$, followed by food processing chemicals $(36.0 \%)$, then sugar 
contents (31.6\%), and lastly saturated fat and sodium (both checked by $25.4 \%$ of respondents). These results indicate that calorie counts on menus are influencing individuals in one way or another to reduce calorie intake.

Thoughts on reasons for obesity: Just over $24 \%$ of respondents reported they strongly agreed obesity was an issue they were concerned about (mean $=3.71$ on a scale of $1-5$ ). Almost $21 \%$ strongly agreed obesity was considered a disease, while $10 \%$ strongly disagreed $($ mean $=3.38$ ). Regarding the effect of fast food as a cause of obesity, $75.6 \%$ believed very much so, with a mean of 6.06 on a scale from 1 to 7 . As for the impact of menu labeling promoting healthy choices, on a scale of 1-7, the mean was 5.14; when asked if it prevented obesity, the mean dropped to 3.94 . Forty-three percent of respondents believed that displaying calorie count promoted healthy choices, while only $21 \%$ believed that it prevented obesity. Respondents' thoughts on causes of obesity are reported in Table 1 below. Respondents working in medical and education fields reported a significantly strong agreement that quality of food and lack of individual health knowledge caused obesity ( $\mathrm{p}=.000$ in both cases).

What respondents do to reduce weight/obesity: Survey respondents were asked what actions they take to lose weight and/or reduce obesity. Just over $74 \%$ reported doing physical exercise and $61 \%$ reported changing their diet. Only a very small amount of respondents take diet pills/bars/shakes (4.4\%) and take medicine prescribed by a doctor (2.6\%). In regards to how respondents change their diet to lose weight, Table 2 below presents the results.

Table 1: Respondents' Thoughts on Causes of Obesity

\begin{tabular}{|l|c|c|c|}
\hline \multicolumn{1}{|c|}{ Cause of obesity } & Most Causing & Least Causing & Mean on 1-7 Scale \\
\hline Quantity of food consumed & $79.9 \%$ & $3.2 \%$ & 6.15 \\
\hline Quality of food consumed & $60.3 \%$ & $6.4 \%$ & 5.47 \\
\hline Short-term gratification & $58.5 \%$ & $6.0 \%$ & 5.48 \\
\hline Food producing/ processing methods & $52.3 \%$ & $3.8 \%$ & 5.36 \\
\hline Irregular eating habits & $49.3 \%$ & $9.6 \%$ & 5.18 \\
\hline Psychological depression & $42.1 \%$ & $7.4 \%$ & 4.94 \\
\hline Lack of individual's health knowledge & $41.8 \%$ & $11.2 \%$ & 4.90 \\
\hline Food additives and preservatives & $37.7 \%$ & $12.5 \%$ & 4.76 \\
\hline Lack of social pressure & $18.1 \%$ & $22.2 \%$ & 3.96 \\
\hline
\end{tabular}

Table 2: Respondents' Diet Changes to Lose Weight

\begin{tabular}{|c|c|c|}
\hline Diet change & Yes & No \\
\hline Have smaller portions & $55.7 \%$ & $44.3 \%$ \\
\hline Cut down on sugars & $50.4 \%$ & $49.6 \%$ \\
\hline Eat more natural/fresh food & $50.0 \%$ & $50.0 \%$ \\
\hline Eat less processed foods & $45.2 \%$ & $54.8 \%$ \\
\hline Cut down on fats & $33.8 \%$ & $66.2 \%$ \\
\hline Follow a low-carbohydrate/high fat diet & $25.4 \%$ & $74.6 \%$ \\
\hline Other activities & $9.2 \%$ & $90.8 \%$ \\
\hline Use Weight Watchers or other programs & $8.8 \%$ & $91.2 \%$ \\
\hline Doing nothing to lose weight & $10.1 \%$ & $89.9 \%$ \\
\hline
\end{tabular}

What the family can do to assist to reduce obesity: Most respondents believed that the family and social support system could have influence in reducing obesity. Respondents believed families could encourage physical activities (90.3\%), cook healthy food (80.0\%), promote a healthy lifestyle (71.3\%), and have home cooked meals (63.0\%). To a much lesser degree, only $12.7 \%$ believed that families should exert pressure. Significantly, Hispanics tended to agree more on exerting some pressure by family than other ethnicities $(\mathrm{p}=.001)$; young individuals (age 18-25 years) also favored family pressure versus other age groups.

What the health care industry can do to reduce obesity: Seventy-seven percent of respondents reported the most important thing the health care industry could do was create awareness of the negative effects of obesity. Fortythree percent reported the second most important thing was to recommend serious action to obese patients.

What the food industry and restaurants can do to reduce obesity: Twenty-three percent of survey respondents strongly agreed they were in favor of reduced portions in restaurants (mean $=3.54$ on a 1-5 Likert scale). When 
asked about the two most important actions restaurants could do to reduce obesity, 50.4\% of respondents reported offering a variety of healthy options, and $40.8 \%$ reported offering reduced portions.

Government regulations and what the government can do to reduce obesity: Seventy-seven percent strongly agreed or agreed with the legalization requiring restaurants to post calorie counts on menus; only $6.1 \%$ disagreed or strongly disagreed; the rest were indifferent. Fifteen percent strongly disagreed that a tax on junk food would impact its purchases, while $14.3 \%$ strongly agreed (mean $=3.13$ ). On what the government could do to reduce obesity, respondents reported the first most important action would be to regulate the use of food preservatives and chemicals (53.5\%); the second most important action would be to create public awareness of obesity problems and monitor accuracy of calorie count information (both ranked first by $11.8 \%$ and ranked $2^{\text {nd }}$ by $24.1 \%$ ); and the third most important action would be to institute health education in schools (ranked $2^{\text {nd }}$ by $11.8 \%$ of respondents and $3^{\text {rd }}$. by $31.6 \%$ ). Fourteen percent of respondents reported that the government should not be involved at all. However, when asked to what extent the government should interfere in fast food companies' practices, $41 \%$ leaned towards no government interference at all (mean $=4.0$ on a scale from 1 to 7 ), and only $25.3 \%$ leaned towards heavy government interference. There was a significant difference between men and women regarding interference of government in fast food industry practices $(\mathrm{p}=.001)$. Women favored more interference by the government than men.

The results of the survey also showed, as previous studies did, mixed behavioral patterns and change based on the calorie counts on menus. The survey results also showed a significant level of awareness, willingness to change, and continuing curiosity to gain more knowledge regarding health, healthy food and eating patterns, and obesity problems. We have a long way to go to beat obesity. Without a doubt, developing and maintaining healthy attitudes regarding diet, physical activity, and intellectually stimulating conversations, could contribute significantly to combat obesity.

\section{CONCLUSION AND RECOMMENDATIONS}

Results showed that many customers, though not all of them, are affected by calorie counts on the menu. However, some were affected to the point of changing their behavior in some way; others were surprised and were curious to know more; others started conversations we could not stop. As mentioned above, no change would be serious unless the individuals intended to change themselves. Temptation to eat more is very challenging, especially since consumption (food, beverages, etc.) is part of our life and will not stop. The theory goes like this: If obesity is a major societal problem (which it is), let all concerned parties work together in a coordinated fashion to inform, motivate, and assist the individual to be well informed, rather than only aware, (a) of obesity and its problems, (b) of what they eat (quantity, quality, nutritional value, and calories of food), and (c) of bad eating habits. When consumers are informed and have a positive attitude and intention to fight obesity, they also will pressure other parties to change their practices (i.e., restaurants, food manufacturing companies, and government).

Let us continue the conversation, step it up, and do more. Government and social institutions should use soft sales to inform consumers, but also look seriously at the FDA approvals of food additives and preservatives, and identify the ingredients that already show to be harmful (especially in the long term, subjecting it to Gama Testing). Healthcare organizations should be serious about obesity—obesity is dangerous for all individuals and is a waste of societal resources. There will continue to be patients and the organizations will be viable and profitable. Food manufacturers and restaurants have an opportunity to differentiate their offerings to be healthier without inflating prices, and still have a competitive advantage. People are going nowhere, and they will continue to eat. Do the right thing. As part of society, some of their profits are being drained to cure their employees. Remember the Bucket Theory of Marketing "with a hole in the pocket" - one makes profits on one side, but loses it on the other side. If the right thing is done, there will be a reward. Do not underestimate the intelligence of consumers. Families and friends, schools, and social support organizations - why not look at ourselves? Our organizations are made of individuals, and many of those individuals suffer from obesity. Do not only talk and educate, but move to accept, motivate, and support members to change, and then celebrate that change to encourage them and others.

Obesity is a problem. Any action, no matter how small, will put us one step toward solving its problem. Instead of only imagining success, if all parties work together, we will have success. Honesty, cooperation, 
coordination, innovation and creativity are claimed traits in our society. Let us use these effectively to solve this growing problem. For those who think it is too idealistic to be implemented and ask for numbers and scientific approaches, we say that we are past that stage as a society. Remember that as an individual, successful professional, government official, corporate executive, you have the power to change yourself and your outcome in order to avoid the plethora of health and economic challenges that accompany obesity.

\section{AUTHOR INFORMATION}

Elias G. Rizkallah currently is a Professor of Marketing, and Coordinator of the Management and Marketing Program at the Zapara School of Business, La Sierra University, Riverside, California, USA. Rizkallah has a Ph.D. in Marketing from J.L. Kellogg Graduate School of Management, Northwestern University. Research interests include strategic marketing planning, consumer behavior, and international marketing. Rizkallah has served eighteen years in academic positions at various universities, and an additional twelve years in international marketing consulting and line management. E-mail: erizkall@lasierra.edu (Corresponding author)

Kimberly E. Feiler is currently co-owner of Fit 2 Be Free, a health and wellness company, and an adjunct faculty in the Health \& Exercise Science Department, College of Arts \& Sciences, La Sierra University, Riverside, California, USA. Feiler has a MSHS in Community Health Education from Western University of Health Sciences. Research interests include healthy living, lifestyle behaviors, nutrition, sports, and physical activity and exercise. Feiler has participated in and coached various sports in her community, and loves to teach about the importance of living a healthful life. E-mail: kfeiler@lasierra.edu

\section{REFERENCES}

1. Benelam, B. (2009). Calories on the menu. Nutrition Bulletin, 34(3), 289-290.

2. Biddle, S., Gorely, T., \& Marshall, S. (2009). Is television viewing a suitable marker of sedentary behavior in young people? Annals of Behavioral Medicine, 38(38), 147-153.

3. Bollinger, B., Phillip, L., \& Sorensen, A. (2012, February). New Stanford study shows posting calories on restaurant menu boards lowers customers' calorie counts per visit. Stanford School of Business. Retrieved from http://www.gsb.stanford.edu/news/starbucks.html

4. Centers for Disease Control and Prevention. (2011, March 3). Health consequences. In Overweight and obesity. Retrieved from http://www.cdc.gov/obesity/causes/health.html

5. Centers for Disease Control and Prevention. (2012, August 13). Adult obesity facts. In Overweight and obesity. Retrieved from http://www.cdc.gov/obesity/data/adult.html

6. Coelho do Vale, R., Pieters, R., \& Zeelenberg, M. (2008). Flying under the radar: Perverse package size effects on consumption self-regulation. Journal of Consumer Research, 35(3), 380-90.

7. Craig, S., \& Caraway, C. (2011, January 26). Fast food consumers use calorie labeling on menu boards to make lower calorie food choices. NYC.gov - NYC Health. Retrieved from http://home2.nyc.gov/html/doh/html/pr2011/pr018-11.shtml

8. Finkelstein, E. A., Trogdon, J. G., Cohen, J. W., \& Dietz, W. (2009). Annual medical spending attributable to obesity: Payer- and service-specific estimates [Abstract]. Health Affairs, 28(5), 822-831. doi:10.1377/hlthaff.28.5.w822

9. Fishbein, M. (1983). An Investigation of the Relationships between Beliefs about an Object and the Attitude toward that Object. Human Relations, 16, 233-240.

10. Hellmich, N. (2009, December 21). Well-informed diners consume fewer calories. USA Today, 04d.

11. Holbrook, M., \& Havlena, W. (1988). Assessing the real-to-artificial generalizability of multi-attribute attitude models in tests of new product designs. Journal of Marketing Research, 25, 25-35.

12. MacQueen, K. (2010). Calories made visible. Maclean's, 123(22), 43-45.

13. Meitus, M., \& Dedrick, J. (2006, September 6). Package deals: How 100-calorie snack portions measure up. Rocky Mountain News. Retrieved from http://m.rockymountainnews.com/news/2006/sep/06/packagedeals-how-100-calorie-snack-portions-up/

14. Miles, B. (2010, April). Attracting customers to your healthy menu offerings requires strategic marketing campaigns. QSR Magazine. Retrieved from http://www.qsrmagazine.com/promotions/marketing-healthconscious?microsite $=589$ 
15. Pulos, E., \& Leng, K. (2010). Evaluation of a voluntary menu-labeling program in full-service restaurants. American Journal of Public Health, 100(6), 1035-1039.

16. Rettner, R. (2011). Obesity's big fat cost to states: $\$ 15$ billion per year. Retrieved from http://www.msnbc.msn.com/id/44241074/ns/health-diet_and_nutrition/

17. Roberto, C., Larsen, P., Agnew, H., Bail, J., \& Brownell, K. (2010). Evaluating the impact of menu labeling on food choices and intake. American Journal of Public Health, 100(2), 312-318.

18. Scott, M., Nowlis, S., Mandel, N., \& Morales, A. (2008). The effects of reduced food size and package size on the consumption behavior of restrained and unrestrained eaters. Journal of Consumer Research, 35(3), 391-405.

19. Shimp, T., \& Kavas, A. (1984). The Theory of Reasoned Action Applied to Coupon Usage. Journal of Consumer Research, 11, 795-809.

20. $\quad$ Sitting can shorten your life. (2010). Harvard Women's Health Watch, 18(2), 7.

21. Skenazy, L. (2008). Snacking delusions destroyed by NYC calorie-posting law. Advertising Age, 79(26), 16.

22. Stutts, M., Zank, G., Smith, K., \& Williams, S. (2011). Nutrition information and children's fast food menu choices. Journal of Consumer Affairs, 45(1), 52-86.

23. Thorn, B. (2012, January 31). Subway balances healthful marketing message. Nation's Restaurant News. Retrieved from http://nrn.com/article/subway-balances-healthful-marketing-message

24. Zarick, K. (2011, July 27). Fast-food calorie counts on menus prompt cuts." USAToday.com. Retrieved from http://yourlife.usatoday.com/fitness-food/diet-mutrition/story/2011/07/Fast-food-calorie-counts-onmenus-prompt-cuts/49678316/1 